\title{
Research on Postgraduate Cultivation Quality in China: A Bibliometirc Analysis
}

\author{
Pengbin Gao* \\ School of Economics and Management \\ Harbin Institute of Technology \\ Weihai, China
}

\author{
Yiduo Song \\ School of Automotive Engineering \\ Harbin Institute of Technology \\ Weihai, China
}

\begin{abstract}
Cultivation quality has become an attracting topic in postgraduate education in the past few decades. Although many scholars have carried out a wide range of research, the researches did not provide a chronological picture of the themes. To give a comprehensive picture of China's postgraduate cultivation quality, bibliometrics analysis methods were employed to analyze the $\mathbf{1 3 5}$ articles collected from Chinese Social Sciences Citation Index (CSSCI) between 1998 and 2019. The distribution characteristics of documents, published journals, research institutions, authors and research methods were revealed in content analysis. The law of change on the research field and research topics were described in co-word analysis with VOSviewer. Based on the results, this study also suggests directions for further work.
\end{abstract}

Keywords-cultivation quality; China's postgraduate education; bibliometric analysis;co-word analysis; VOSviewer

\section{INTRODUCTION}

With the rise and development of the country, China's demand for talents has been increasing year by year, and more and more attention has been paid to the cultivation of talents. Graduate education is just a way to cultivate highlevel talents. How to improve the quality of graduate education becomes particularly important.

After more than 40 years of development, China's graduate education has initially formed a certain training model with Chinese characteristics. According to statistics, by 2018 there are 2.73 billion graduates, which include 389.5 million doctoral degree candidates and 2.34 million master degree candidates. The state has attached great importance to the quality of postgraduate education and taken many measures to continuously improve the quality assurance system, which promotes the healthy and smooth development of graduate education. In April 2013, the Ministry of Education, National Development and Reform Commission and Ministry of Finance jointly issued Opinions on Deepening the Reform of Postgraduate Education, which clearly focus on the importance of cultivation quality.

Some scholars analyzed and gave some advice to promote the quality of graduate education. Abiddin et.al (2013) suggested that Institutions should enhance the quality of higher education for graduate research students

This work was supported by the Research Project of Postoraduate Education Reform in Harbin Institute of Technology and Research Project of Postgraduate Education and Teaching Reform in Harbin Institute of Technology (Weihai) developing distinguished human capital[1]. Doran et.al (2014) pointed out that the higher quality graduate training experience can play an important role in promoting student's development[2]. Verma (2016) modified quality model to improve service quality of Govt. Degree college[3] Wamala et al (2013) suggested that the introduction of the examination can enhance the quality of education outcomes[4]. Belecina and Ocampo (2017) thought that the tracer study can be used for the enhancement of quality course programs offered in higher education institutions[5].

In summary, numerous reviews have provided various research issues, but these researches were more dependent on subjective analysis and can't disclose precisely the nature of the field in China. Specifically, this study adopted the quantitative method to analyze the domain as a whole.

\section{RESEARCH DESIGN}

\section{A. Research Method}

Content analysis is a systematic and quantitative method, which can give a comprehensive description of the status of information from literature. The key processes of content analysis include determining the analysis unit and analyzing the categories. In this paper, year, journals, institutions and research types were used to analyze the distribution of papers. In addition, research content was also analyzed.

Co-word analysis draws upon the assumption that a paper's keywords can give an adequate description of content. VOSviewer is a software tool for constructing and visualizing bibliometric maps. Unlike most computer programs that are used for bibliometric mapping, VOSviewer is especially useful for displaying large bibliometric maps in an easy-to-interpret way, and pay more attention to drawing and clustering. So we hope to use it to make a clearer and richer keyword co-occurrence analysis of undergraduate research.

\section{B. Data Collection}

The data were collected through a set of procedures. First, Chinese Social Sciences Citation Index (CSSCI) database was selected as the data source. Second, according to the purpose of this study, the search criteria were formulated by including "cultivation quality" and "postgraduate". The data were extracted in September 2019, 
with the search in the topic field covering the period from 1998 to 2019. Finally, a total of 135 articles were retrieved and selected as the analysis sample.

\section{RESULTS OF CONTENT ANALYSIS}

\section{A. Number of Papers}

After analyzing the literature collection of postgraduate cultivation quality from the CSSCI database, the publication growth from 1998 to 2019 as shown in Fig. 1. There has been a steady increase since 1998 and the quantity reached a high tide in 2011.

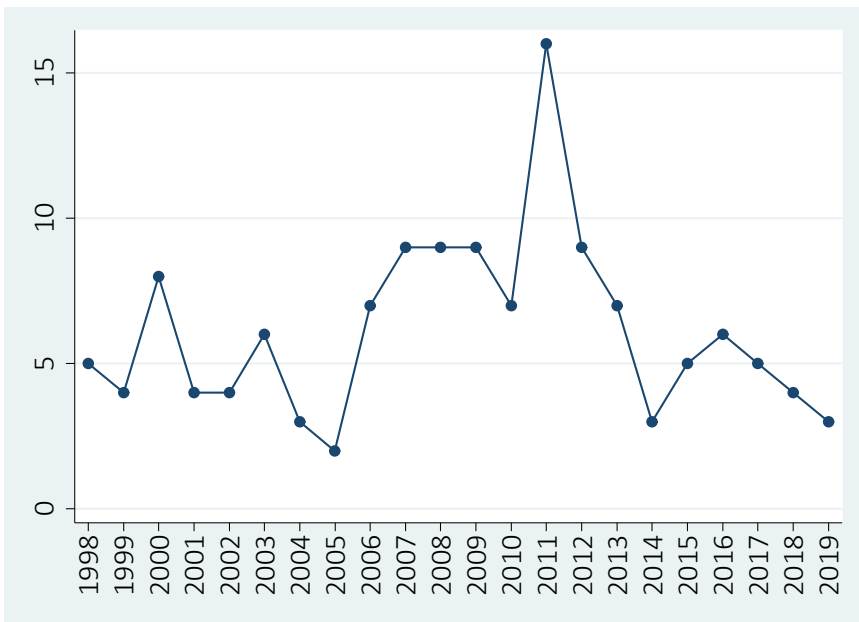

Fig. 1. Growth of literature over time

\section{B. The Distribution of Journals}

From 1998 to 2019, 46 journals contributed 135 articles. We ranked journals on their total contribution to the list of articles. The top 14 journals with the largest number of publications were identified, which is presented in Fig.2. Most of them are educational journals, Academic Degrees \& Graduate Education is the journal with the highest number of papers, followed by Journal of Graduate Education and China Higher Education.

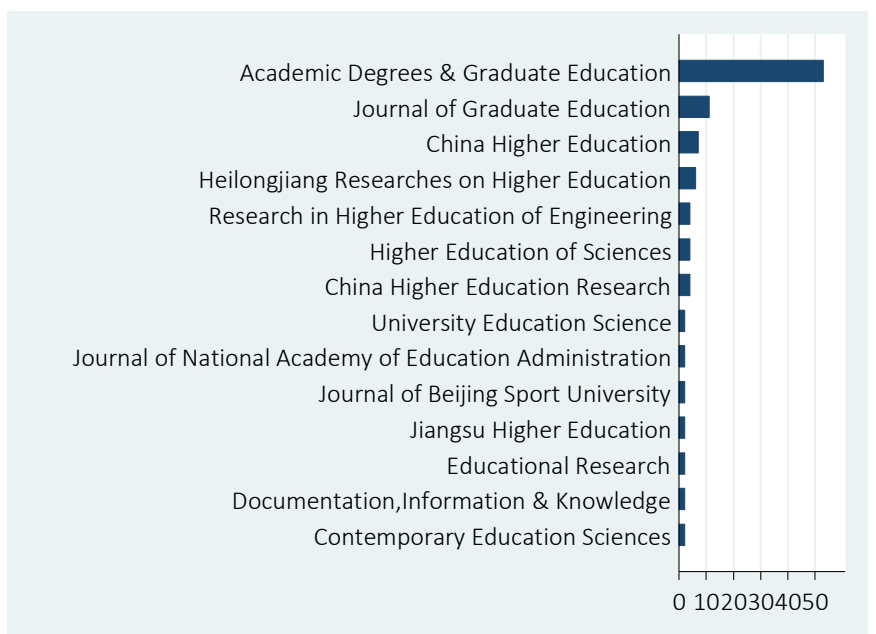

Fig. 2. Leading journals contributors

\section{The Distribution of Institutions}

During the 22 year period of the study, the 135 first authors were affiliated with 92 institutions. The top 22 universities are ranked in Fig. 3. According to the Fig. 3, Zhe Jiang University and Renmin University of China are the institutions with the highest number of papers, followed by East China Normal University and Beihang University. It is suggested that top universities usually pay more attention to the quality of graduate education.

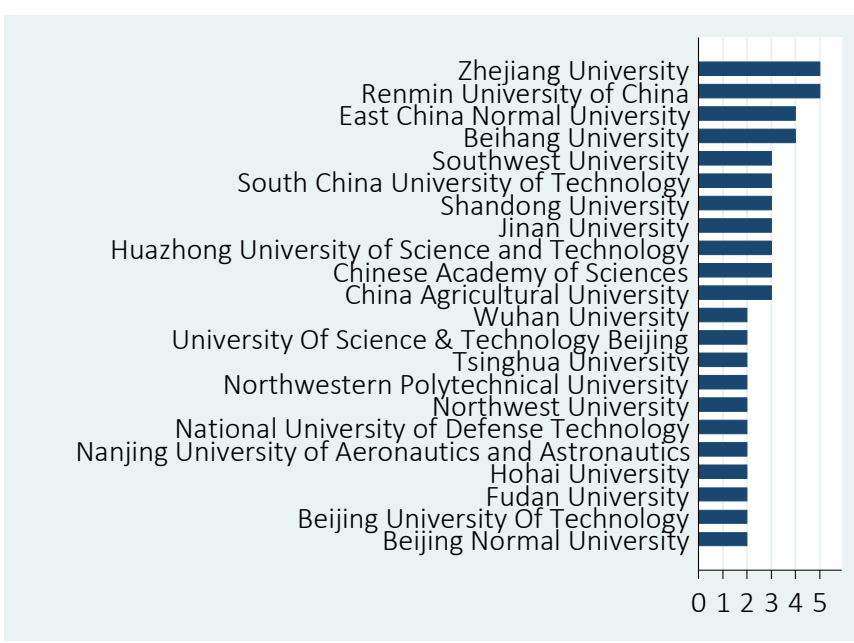

Fig. 3. Main institutions

D. The Distribution of Authors

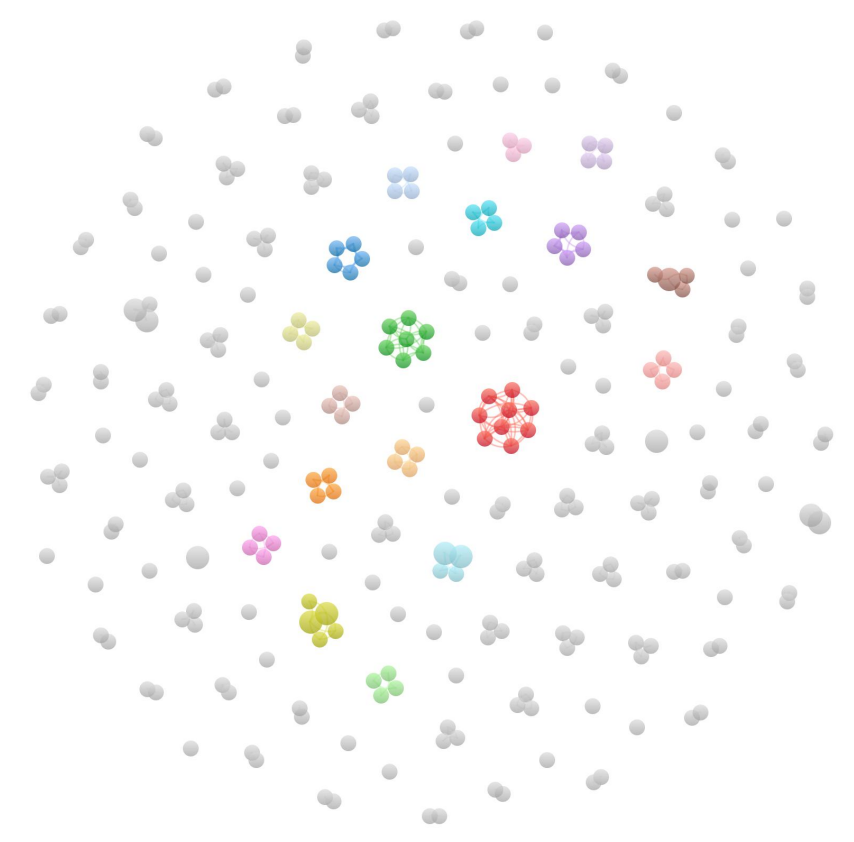

Fig. 4. Co-authorship network

During the 22 year period of the study, the 290 authors participated in the publication of 135 papers. But only 11 aauthors wrotetwo papers, and the rest just published one paper. The co-authorship network is shown in Fig.4. 
The fifth cluster focused on doctor and factor, including

According to the Fig. 4, there is little cooperation among scholars, and they are basically independent in research.

\section{E. The Distribution of Research Method}

As concerning research type and methodology, we distinguished among theoretical, case and quantitative contributions, which are presented in Fig.5.

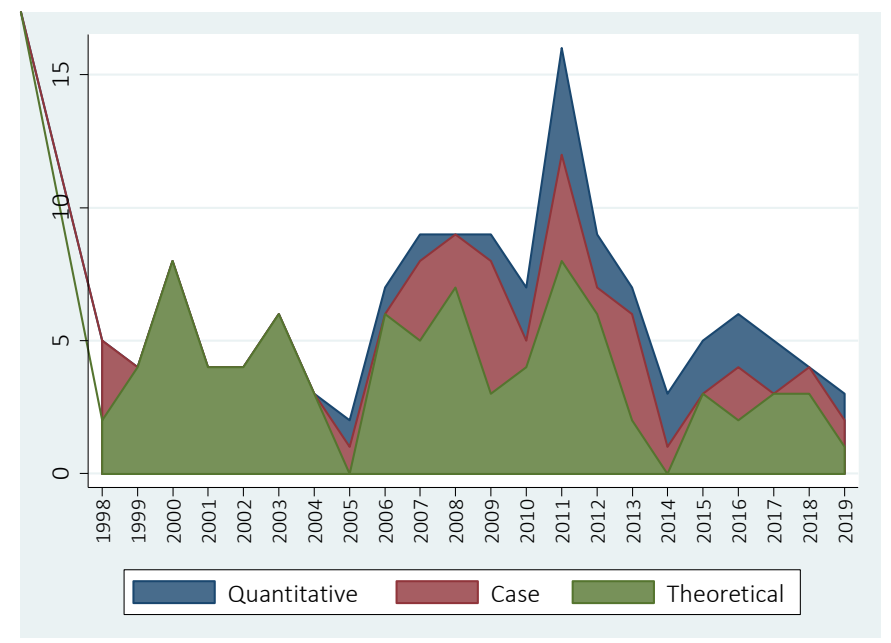

Fig. 5. Frequencies of research types

According to the result of Fig. 5, there are more theoretical researches from 1998 to 2019, which suggests this method is the main form. At the same time, quantitative and case researches began to increase in 2005 gradually.

\section{RESUlTS OF CO-WORD ANALYSIS}

Generally, searching keywords for research papers is a convenient way to retrieve data for studying a research field. Using the VOSviewer 1.6.13, this paper also conducted a statistical analysis of keywords, demonstrating the most popular research topics.

\section{A. Cluster Analysis}

Fig. 6 visualized the relationships among the highfrequency keywords (over 3). The study categorized those keywords that appeared multiple times into six themes.

The first cluster focused on training and management, including Education Reform, Graduate Management, Innovation Ability, Postgraduate Education, Postgraduate Training, Process Management.

The second cluster focused on tutor and subject, including Academic Degree, Graduate Tutor, Quality of Postgraduate, Subject, Tutor Team.

The third cluster focused on evaluation and guarantee, including Evaluating Indicator, Guarantee System, Master Students, Postgraduate Education Training, Professional Degree.

The fourth cluster focused on dissertation and quality, including Dissertation, Evaluation, Graduate Students, Quality.
Doctor, Doctoral Student, Influence Factor.

The sixth cluster included Cultivation Quality and Professional Degree Graduate Student.

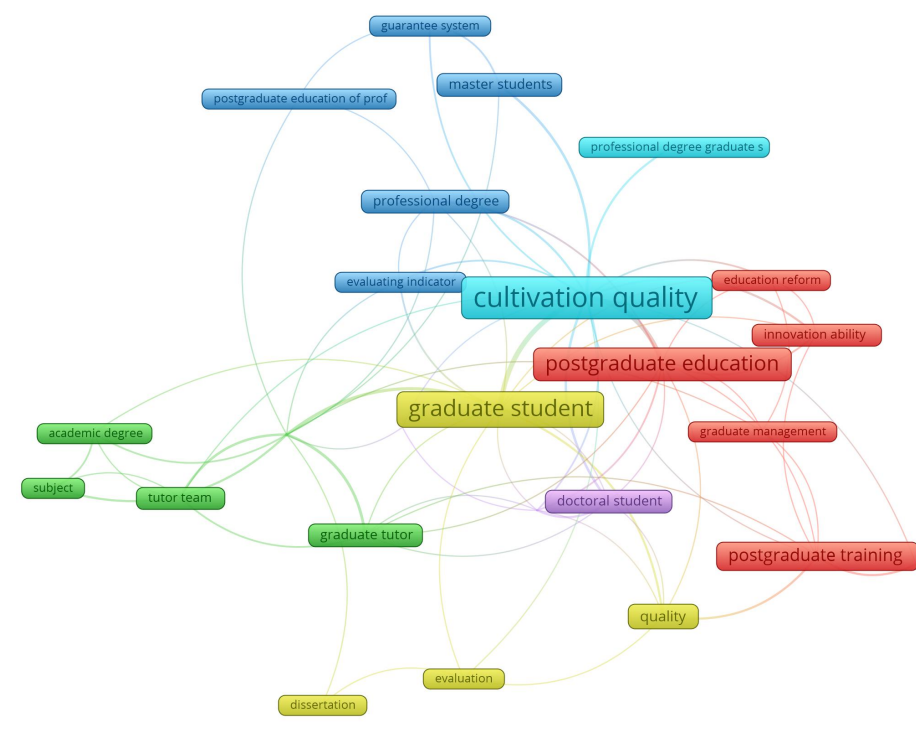

Fig. 6. Keyword co-occurrence network

\section{B. Hot Topics}

According to Fig. 7, in recent years, the most prevalent keywords were "Professional Degree Graduate Student","Dissertation" and "professional degree", etc.

By contrast, traditional hotspots include"subject", "tutor team", "graduate tutor" and "academic degree" etc. These results can be seen from Fig. 7 .

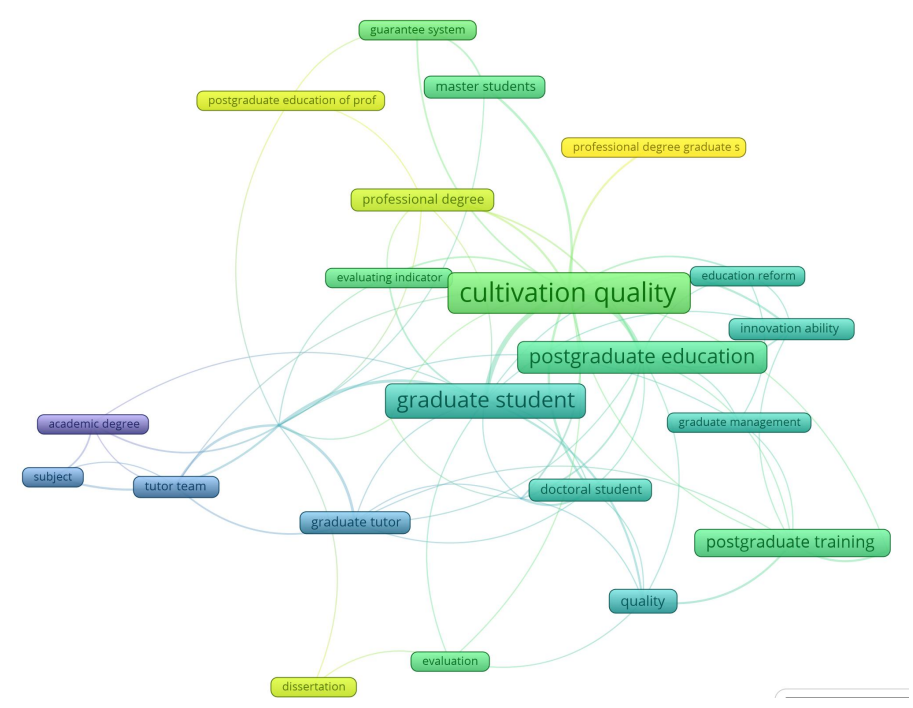

Fig. 7. Overlay visualization of keyword co-occurrence based on year of publication 
Secondly, qualitative analysis methods were used in

\section{Main Content}

\section{1) Evaluation of cultivation quality}

The research in this area is mainly manifested in two aspects.

Firstly, some scholars analyzed the problems existing in the current postgraduate cultivation quality, and then put forward targeted countermeasures and suggestions [6-7].

Secondly, some scholars construct the cultivation quality evaluation index system from the theoretical level and conduct empirical analysis[8-9].

\section{2) Influencing factors of culture quality}

In addition to summing up the influencing factors from multiple aspects, the researches in this area also carried out in-depth research on some specific factors.

Firstly, some scholars used qualitative analysis, including dissertation online review, postgraduate award system, innovation practice platform, system deficiency, cultivation scale, process management based on teacherstudent relationship and integration of production, learning and research, etc.

Secondly, some scholars used quantitative analysis, including the characteristics of students, funding level and type, scientific research participation, teacher-student relationship Department, academic motivation, training environment.

\section{3) Cultivation quality of non-management majors}

The research in this area mainly included two aspects.

Firstly, qualitative analysis methods were used in some researches, including the discussion on improving the training quality of "Marxism research in China", the summary of medical specialty combined with specific practice and the experience of postgraduate training quality of Control Science, and the impact of process feedback on the cultivation quality of master of engineering, the curriculum design methods based on team and experiment improving the cultivation quality of medical master.

Secondly, quantitative analysis methods were used in some researches, including the investigation and analysis of the cultivation quality of library and information major, medical major, agriculture-related major, and the construction and application of the evaluation index system for the cultivation quality of sports majors.

\section{4) Cultivation quality of management majors}

The research in this area mainly included two aspects. Firstly, quantitative evaluation was used in some researches, including the introduction of the evaluation indicators of the international management discipline, the construction of indicators in specific countries for research and testing. analyzing the importance of process control.

\section{CONCLUSION}

Based on bibliometrics and co-words analysis, this study produced a reasonable result. This study can analyze the characteristics and trends of the previous studies, and describe systematically development situations, which can give the reference for other researches.

The results of the co-word analysis show that the research focuses mainly on the quality, tutor, dissertation, guarantee, subject, management, capability, evaluation and so on.

Our study has got some valuable conclusions, but it is not free from limitations. In the future, we can enlarge the sources of publication and use other quantitative approaches to learn more about the intellectual structure of research of cultivation quality in China's postgraduate education.

\section{ACKNOWLEDGMENT}

This work was supported by the Research Project of Postgraduate Education Reform in Harbin Institute of Technology, Research Project of Postgraduate Education and Teaching Reform in Harbin Institute of Technology (Weihai)

\section{REFERENCES}

[1] Abiddin N Z, Ismail A, Taniredja T. Enhancing Quality of Higher Education for Graduate Research Students Development[J]. Educare, 2013, 5(2):32-34

[2] Doran J M, Meyerson D A, El-Ghoroury N H. Promoting a higher quality graduate training experience: A student perspective on the HSPEC Blueprint for Health Service Psychology Education and Training[J]. Training and Education in Professional Psychology, 2014, 8(1): 12

[3] Verma G R. Achieving Quality in Higher Education: Road to Academic Excellence in Graduate and Post-Graduate Institution of Jammu and Kashmir[J]. ZENITH International Journal of Multidisciplinary Research, 2016, 6(3): 70-82.

[4] Wamala R, Buyinza M. Quality of Education Outcomes: The Role of the Graduate Management Admission Test[J]. American Journal of Business Education, 2013, 6(1): 141-148.

[5] Belecina R R, Ocampo Jr J M. Towards Quality Graduate Mathematics Teacher Education: A PNU CGSTER Tracer Study[J]. SOSIOHUMANIKA, 2017, 10(1): 45-56.

[6] Renshan Zhang, Songshan Li. Research on the Countermeasures to Improve the Quality of Postgraduate Training $[\mathrm{J}]$. Theory and Practice of Education,2015,35(18):3-5 (In Chinese)

[7] Jia-bin Yu.Study of Cultivation Quality of Full-time Graduate Students for Professional Degree in Local Colleges[J].Heilongjiang Researches on Higher Education,2015,258(10):112-114 (In Chinese)

[8] Liang Zhen, Jun Kang, Shuang Ying.Construction of a Quality Evaluation and Assurance System for Professional Master's Degree Programs[J].Journal of Graduate Education,2012,6:52-54 (In Chinese)

[9] Yong Chen, Wen Xiao. An Empirical Study on the Quality Evaluation of Graduates from the Perspective of Stakeholders[J].Research in Higher Education of Engineering,2016,6:168-176 (In Chinese) 